\title{
Tráfico de Pessoas para fins de exploração do trabalho na cidade de São Paulo*
}

\author{
Paulo Illes** \\ Gabrielle Louise Soares Timóteo ${ }^{* * *}$ \\ Elaine da Silva Fiorucci*****
}

\begin{abstract}
Resumo
Este artigo busca contextualizar, em linhas gerais, o fluxo de imigrantes bolivianos para fins de trabalho nas oficinas de costura da cidade de São Paulo, demonstrando a interface dessa imigração com o tráfico de migrantes e o tráfico de pessoas. Por meio de depoimentos, são apresentadas as recorrentes dificuldades enfrentadas pelas trabalhadoras imigrantes.
\end{abstract}

Palauras-chave: Tráfico de Pessoas, Imigrantes, Gênero, Trabalho, São Paulo.

\footnotetext{
* Recebido para publicação em setembro de 2008, aceito em outubro de 2008.

*** Coordenador do Centro de Apoio ao Migrante/SPM/CNBB. spm.cami@terra.com.br

***** Advogada e mestranda em Direito do Trabalho na Faculdade de Direito da Universidade de São Paulo - USP. gabrielle.timoteo@usp.br

**** Psicóloga do Centro de Apoio ao Migrante /SPM /CNBB. elaine_fiorucci@yahoo.com.br

cadernos pagu (31), julho-dezembro de 2008:199-217.
} 
Tráfico de Pessoas na cidade de São Paulo

\author{
Human Trafficking for Labour Exploitation
}

in the City of São Paulo

\begin{abstract}
This article seeks to contextualize, along general lines, the Bolivian migratory flow towards sweatshops in the city of São Paulo, showing the interaction between this migratory flow, migrant smuggling and human trafficking. The most frequent problems faced by the migrant women are presented in testimonials.
\end{abstract}

Key Words: Human Trafficking, Immigrants, Gender, Labour, São Paulo. 
Paulo Illes, Gabrielle Timóteo, Elaine Pereira

\section{Apresentação}

Este artigo tem por objetivo descrever, em linhas gerais, o fluxo de imigrantes bolivianos para fins de exploração do trabalho nas oficinas de costura da cidade de São Paulo, destacando a situação da mulher imigrante nesse processo. Assim, optamos por desenvolver este trabalho a partir da observação dos atendimentos efetuados no Centro de Apoio ao Migrante (CAMI). Os depoimentos aqui relatados foram colhidos durante consultas realizadas ao longo dos três anos de existência do Centro. ${ }^{1}$

O Centro de Apoio ao Migrante - instituição criada em 22 de julho de 2005 pelo Serviço Pastoral dos Migrantes - é uma entidade filantrópica ligada à CNBB (Conferência Nacional dos Bispos do Brasil) e gerida por um Conselho Político e Pedagógico Multidisciplinar. O Centro de Apoio atua diretamente no atendimento às vítimas e no enfretamento ao tráfico de imigrantes - especialmente sul-americanos "contrabandeados" da Bolívia, Paraguai e Peru para trabalharem em condições análogas à escravidão nas oficinas de costuras de São Paulo.

Em linhas gerais, o principal trabalho do Centro consiste em regularização migratória, assessoria jurídica especializada, assistência psicossocial, articulação com organismos governamentais e não governamentais. De julho de 2005 a julho de 2008, portanto, em três anos de trabalho, passaram pelo Centro de Apoio mais de 18 mil imigrantes de 20 nacionalidades. Entre os imigrantes que procuram pelo atendimento no CAMI $90 \%$ são oriundos da Bolívia, 3,5\% do Paraguai, 3\% do Peru. A alta procura dos imigrantes bolivianos deve-se ao acordo de Regularização Migratória firmado entre Brasil e Bolívia em 2005 (que possibilitou a regularização migratória desses nacionais mediante o preenchimento de certos requisitos). Os imigrantes procuram o Centro principalmente para regularizar sua situação

1 Para evitar a proliferação de notas, após a citação dos depoimentos será indicada a data em que foram colhidos. 
Tráfico de Pessoas na cidade de São Paulo

migratória, denunciar trabalho degradante e escravo, violência contra a mulher, exploração de menores, violência institucional.

\section{As migrações no contexto global}

O recém-iniciado século XXI tem demonstrado, em diversos países do mundo, níveis recordes de imigração. De acordo com dados do Fundo de População das Nações Unidas - Unfpa -, atualmente, existem mais de 200 milhões de migrantes no mundo. ${ }^{2}$

Cerca de $55 \%$ dos migrantes internacionais vivem em países em desenvolvimento e $45 \%$ em países desenvolvidos. Nos países em vias de desenvolvimento, a porcentagem de imigrantes na população total tem-se mantido estável ao longo dos últimos 35 anos, flutuando sempre perto de $1,6 \%$. Nos países desenvolvidos, a porcentagem de imigrantes duplicou no mesmo período, ainda que, em média, não esteja acima de cerca de 5\% (Entzinger, 2001:1).

No Brasil, os imigrantes internacionais registrados ultrapassam pouco mais de 1.250.000. É importante frisar que os números da Tabela 1, a seguir, só envolvem estrangeiros registrados no Brasil, isto é, aqueles que estão em situação migratória regular. Considerando os imigrantes irregulares $e$ indocumentados tem-se uma estimativa de pouco mais de 2 milhões, representando quase $1 \%$ da população total do país. ${ }^{3}$

\footnotetext{
2 Dados retirados de reportagem veiculada no site da ONU em 06/04/2006: http://www.onu-brasil.org.br/view_news.php?id=3879 (último acesso em 12/08/2007).

3 Uma reportagem da BBC-Brasil (27 de março de 2008), citando dados da Polícia Federal e do Ministério Público do Trabalho, mostra que o Brasil tem sido um destino escolhido por um número cada vez maior de imigrantes em busca de oportunidades. Ainda segundo a reportagem, de 2004 a 2007, houve um aumento de $51 \%$ no total de novos estrangeiros no país; quando se consideram apenas países sul-americanos, o aumento foi de 144\% entre 2004 e 2007.
} 
Tabela 1

Principais Grupos Latino-Americanos Registrados no Brasil

\begin{tabular}{|l|r|}
\hline $\begin{array}{l}\text { Argentinos regularmente } \\
\text { registrados no Brasil }\end{array}$ & 54.427 \\
\hline $\begin{array}{l}\text { Bolivianos regularmente } \\
\text { registrados no Brasil }\end{array}$ & 47.692 \\
\hline $\begin{array}{l}\text { Uruguaios regularmente } \\
\text { registrados no Brasil }\end{array}$ & 37.284 \\
\hline $\begin{array}{l}\text { Chilenos regularmente } \\
\text { registrados no Brasil }\end{array}$ & 33.263 \\
\hline $\begin{array}{l}\text { Bolivianos regularmente } \\
\text { registrados em São Paulo }\end{array}$ & 35.050 \\
\hline $\begin{array}{l}\text { Fonte: Luciano Pestana, Diretor do Departamento de } \\
\text { Estrangeiros do Ministério da Justiça - Fevereiro de 2008. }\end{array}$
\end{tabular}

\section{Brasil: um país de trabalhadores migrantes}

Em termos globais, a imigração foi sempre um fato marcante $e$ que trouxe consigo um vasto conteúdo de transformação sócio-cultural, política e econômica. Em linhas gerais, historicamente, no Brasil, após o genocídio das populações nativas praticado pelos conquistadores, assistimos, durante mais de 300 anos, o tráfico de negros africanos para trabalharem como escravos. A abolição da escravidão, descolada de qualquer planejamento ou política social que visasse à inclusão dos libertos, fez com que os ex-escravos continuassem alijados econômica e socialmente e fossem obrigados a se deslocarem para as periferias urbanas.

No final do século XIX e início do XX, a conjuntura externa aliada à política de branqueamento do Brasil fez com que o país se tornasse um forte centro de recepção de trabalhadores imigrantes, sobretudo europeus. ${ }^{4}$

4 No final da década de 50, a Europa deixa de ser uma região de emigrantes e passa a ser um pólo de atração imigratória para diversas partes do mundo. 
Tráfico de Pessoas na cidade de São Paulo

O Brasil recebeu perto de cinco milhões de imigrantes entre 1819 e fins da década de 1940. Os três principais contingentes - italianos, portugueses e espanhóis somaram mais de $2 / 3$ do total, seguidos pelos alemães $e$ japoneses. Outros grupos foram numericamente menos expressivos - caso dos russos, austríacos, sírio-libaneses e poloneses. Até meados da década de 1880 a maior parte dos imigrantes dirigiu-se, sob os auspícios do governo imperial, para o sul, situação que se modificou durante a "grande imigração", quando São Paulo passou a ser o destino da maioria dos imigrantes entrados no país (Seyferth, 2008:01).

Especialmente na segunda metade do século $\mathrm{XX}$, o Brasil sofreu uma migração interna notável, na qual grandes contingentes populacionais deslocaram-se do campo para a cidade, bem como de regiões menos desenvolvidas $e$ pauperizadas para regiões mais dinâmicas economicamente. Um exemplo desse fluxo interno são os migrantes nordestinos que se dirigiram para cidades como São Paulo e Rio de Janeiro (Sezyshta, 2004:36)

O fluxo de imigrantes bolivianos se intensificou, especialmente, na década de 1980. Esse movimento populacional foi motivado por razões econômicas, sendo que o objetivo principal dos bolivianos que para aqui migraram era o de trabalhar. Entretanto, não é possível falar do fluxo de bolivianos dissociado da imigração coreana.

Inicialmente, na década de 1960, os coreanos envolveram-se no comércio têxtil, trabalhando para empresários de origem judaica. Entretanto, a partir da década de 1970, eles se tornaram os principais donos das oficinas de costuras de São Paulo. A forma de produção nas oficinas de coreanos era de caráter familiar - todos os membros estavam envolvidos de alguma forma no processo produtivo. $\mathrm{O}$ trabalho era precário e com a expansão da demanda os donos de oficinas acabaram por contratar outros imigrantes coreanos como seus empregados. Com o passar do 
tempo, os coreanos começaram a empregar mão-de-obra boliviana, que aceitou a condição de "cama adentro" - que consiste em trabalhar, comer e dormir no mesmo local de trabalho. ${ }^{5}$

Embora sejam maioria, não são somente trabalhadores bolivianos que alimentam esse mercado de mão-de-obra; atualmente, é possível identificar contingentes representativos de peruanos e paraguaios, por exemplo. Um ponto relevante a ser notado é que alguns imigrantes latino-americanos, que já estão no Brasil há alguns anos, têm montado oficinas de costuras e trazido, de forma irregular, seus patrícios para se submeterem ao regime de exploração. ${ }^{6}$

\section{Trabalho escravo e mão-de-obra irregular}

O tema do trabalho escravo de imigrantes latino-americanos no Brasil tem sido denunciado e discutido. O trabalho escravo é, sobretudo, conseqüência de um sistema complexo, no qual está presente a desigualdade social, a falta de oportunidades, a vulnerabilidade social, a falta de políticas sociais, $\mathrm{o}$ subdesenvolvimento econômico, a rede de tráfico de pessoas, os entraves jurídicos que dificultam a legal permanência $e$ regularização do trabalhador imigrante ${ }^{7}$ etc.

$\mathrm{O}$ imigrante latino-americano indocumentado que trabalha no setor de costura no Brasil tem seus direitos humanos sistematicamente violados. Dezenas de reportagens foram realizadas buscando denunciar as condições enfrentadas por esses

\footnotetext{
${ }^{5}$ Sobre esses fluxos de coreanos e bolivianos, ver Azevedo (2005).

${ }^{6}$ Essas afirmações são fruto da observação direta sobre a comunidade de imigrantes latino-americanos desenvolvida nas atividades conduzidas no CAMI.

7 Um exemplo é o debate acerca do Estatuto do Estrangeiro (Lei 6.815/80). Essa Lei foi forjada durante o governo militar e seu teor exprime grande preocupação com a segurança nacional e acaba por tratar o estrangeiro como suspeito. Muito é dito sobre a necessidade de um novo estatuto que se coadune com as normas de direitos humanos e tratados internacionais ratificados pelo Brasil.
} 
Tráfico de Pessoas na cidade de São Paulo

trabalhadores. Traços recorrentes nas caracterizações jornalísticas são jornadas exaustivas de até 18 horas; salários inferiores ao mínimo; má alimentação; retenção de documentos; cerceamento do direito de ir e vir por meio de portas trancadas e/ou câmeras de vigilância; descontos nos pagamentos relativos a despesas com alimentação, moradia e viagem Bolívia-Brasil; condições insalubres, como pouca luminosidade, deficiência de instalações sanitárias e de moradia (que, muitas vezes, confundem-se com o local de trabalho sendo o local de dormir um colchonete estendido perto da própria máquina de costura do trabalhador); risco de incêndio e explosões devido a más instalações elétricas; crianças trancafiadas em quartos escuros ou amarradas ao pé da máquina de costura durante a jornada de trabalho dos pais; alto índice de tuberculose; intensa coação psicológica por parte dos patrões, que ameaçam denunciar os trabalhadores às autoridades migratórias etc. Como aponta Patussi (2005:217),

\begin{abstract}
A grande maioria dos bolivianos trabalha e mora no mesmo local insalubre onde estão instaladas as oficinas de costura, o que traz sérios problemas para a saúde. Um dos mais graves é a tuberculose. Uma jornada normal, no ramo da costura, é de 12 a 14 horas diárias, mas muitos trabalham das $7 \mathrm{~h}$ à $0 \mathrm{~h}$. Um imigrante que não quis se identificar declarou: "eu não podia reclamar, não podia fazer valerem os meus direitos porque eu pensava que não tinha nenhum. Eu não tinha documento aqui”.
\end{abstract}

De fato, conforme relatos de trabalhadores que passaram pelo Centro, pode-se concluir que a maioria recebe - quando recebe - uma remuneração média mensal de $R \$ 350,00$, ou seja, menor do que um salário mínimo. Entretanto, sua jornada de trabalho é em média de 14 horas diárias, 6 dias por semana. Assim, se fizermos um cálculo aproximativo, concluiremos que 
trabalham 84 horas por semana. ${ }^{8}$ Lembrando que, caso uma peça não saia perfeita, será descontado do costureiro o preço de mercado, o que significa que em determinadas situações o trabalhador pode começar o mês com dívidas.

Em relação à habitação, existem casos de famílias morando no próprio local de trabalho, acomodando-se em beliches $e$ usando armários compartilhados; aglomerando-se em cômodos únicos de habitações coletivas (popularmente denominadas cortiços) com uma só cozinha e um único banheiro (sendo que o aluguel de um quarto na região central da capital não sai por menos de $\mathrm{R} \$ 280.00$ ); ou morando de forma precária com parentes.

Um dos fatores mais preocupantes no aspecto da saúde desses imigrantes é no que se refere a doenças sexualmente transmissíveis, ocorrências de tuberculose e lesões por esforço repetitivo (como tendinites, artroses, etc.).

Quando um trabalhador procura ajuda em organizações de apoio geralmente pode ser percebida sua timidez, baixa autoestima, postura desconfiada, sofrimento, sendo preciso ganhar-lhe a confiança aos poucos. Entre as várias preocupações dos imigrantes, as mais recorrentes são: regulamentação da situação jurídica no Brasil, cobrança de salários devidos, separação de casais ${ }^{9}$, pedido de guarda dos filhos. ${ }^{10}$ Ademais, ocorrem casos em que os imigrantes sofrem opressão do próprio poder público. Há situações em que algumas diretoras de unidades de ensino,

\footnotetext{
8 A CF (artigo 7, XII) estabelece a duração do trabalho normal não superior a 8 horas diárias e 44 horas semanais.

9 As brigas entre os casais são provenientes, na maioria das vezes, da fadiga imposta pelo seu cotidiano; em certas situações, após algumas horas de conversa, assistidos por profissionais do CAMI, acabam se reconciliando.

${ }^{10}$ Os pedidos de guarda são tanto em casos nos quais os pais a perderam por força judicial e tentam recuperá-la, quanto em casos nos quais a mulher foi abandonada com o filho pelo marido ou companheiro.
} 
Tráfico de Pessoas na cidade de São Paulo

desinformadas ${ }^{11}$, não querem aceitar matrículas de filhos de imigrantes por falta de documentos.

\section{Contrabando de imigrantes e tráfico de pessoas}

O tráfico de migrantes (ou contrabando de imigrantes) e o tráfico de pessoas são figuras que podem aparecer quando tratamos do tema migrações internacionais. O tráfico de migrantes e o tráfico de pessoas são ilícitos distintos. O conceito de tráfico de migrantes pode ser encontrado no Protocolo Adicional à Convenção das Nações Unidas contra o Crime Organizado Transnacional, relativo ao Combate ao Tráfico de Migrantes por Via Terrestre, Marítima e Aérea. ${ }^{12} \mathrm{O}$ artigo 3 dispõe que

a expressão "tráfico de migrantes" significa a promoção, com o objetivo de obter, direta ou indiretamente, um benefício financeiro ou outro benefício material, da entrada ilega $1^{13}$ de uma pessoa num Estado Parte do qual essa pessoa não seja nacional ou residente permanente.

O Protocolo (artigo 6) esclarece que é passível de criminalização, além do tráfico de migrantes, a elaboração de documento de viagem ou de identidade fraudulento, bem como sua obtenção, fornecimento ou posse com objetivo de possibilitar o tráfico ilícito de migrantes. Ademais, também é passível de punição a viabilização da permanência de uma pessoa não nacional ou residente permanente sem preencher as condições necessárias

${ }^{11}$ Cf. Resolução SE no 10, de 2 de fevereiro de 1995, que dispõe sobre matrícula de aluno estrangeiro na rede estadual de ensino fundamental e médio de São Paulo; e a deliberação CEE n ${ }^{\circ}$ 16/97.

12 O Protocolo tem como objetivo prevenir e combater o tráfico de migrantes, bem como promover a cooperação entre os Estados Partes com esse fim, protegendo ao mesmo tempo os direitos dos migrantes, objeto desse tráfico. Cf. Decreto n ${ }^{\circ}$ 5016/04.

${ }^{13}$ A expressão "entrada ilegal" significa a passagem de fronteiras sem preencher os requisitos necessários para a entrada no Estado de acolhimento. 
para permanecer legalmente em um Estado, recorrendo a meios ilegais.

Por sua vez, a definição de tráfico de pessoas pode ser encontrada no Protocolo Adicional à Convenção das Nações Unidas contra o Crime Organizado Transnacional Relativo à Prevenção, Repressão e Punição do Tráfico de pessoas, em especial mulheres e crianças, mais conhecido como Protocolo de Palermo. ${ }^{14} \mathrm{O}$ documento tem como objetivos (i) prevenir $e$ combater o tráfico de pessoas, prestando uma atenção especial às mulheres $e$ às crianças; (ii) proteger $e$ ajudar as vítimas desse tráfico, respeitando plenamente os seus direitos humanos; e (iii) promover a cooperação entre os Estados Parte. Segundo o art. 3 do referido instrumento:

a) A expressão "tráfico de pessoas" significa o recrutamento, o transporte, a transferência, o alojamento ou o acolhimento de pessoas, recorrendo à ameaça ou uso da força ou a outras formas de coação, ao rapto, à fraude, ao engano, ao abuso de autoridade ou à situação de vulnerabilidade ou à entrega ou aceitação de pagamentos ou benefícios para obter o consentimento de uma pessoa que tenha autoridade sobre outra para fins de exploração. A exploração incluirá, no mínimo, a exploração da prostituição de outrem ou outras formas de exploração sexual, o trabalho ou serviços forçados, escravatura ou práticas similares à escravatura, a servidão ou a remoção de órgãos;

b) O consentimento dado pela vítima de tráfico de pessoas tendo em vista qualquer tipo de exploração descrito na alínea "a" do presente artigo será considerado irrelevante se tiver sido utilizado qualquer um dos meios referidos na alínea "a";

c) O recrutamento, o transporte, a transferência, o alojamento ou o acolhimento de uma criança para fins de

${ }^{14}$ Cf. Decreto no 5017/04. 
Tráfico de Pessoas na cidade de São Paulo

exploração serão considerados "tráfico de pessoas" mesmo que não envolvam nenhum dos meios referidos da alínea "a" do presente Artigo;

d) O termo "criança" significa qualquer pessoa com idade inferior a dezoito anos.

É importante mencionar que comumente é feita distinção doutrinária entre tráfico de migrantes e tráfico de pessoas no que diz respeito ao consentimento da vítima. No caso do tráfico de migrantes, é entendido que a pessoa consente em ser traficada com o objetivo de cruzar uma fronteira ilegalmente. No tráfico de pessoas, se a vítima consentir, será por coação do aliciador ou por estar iludida com promessas que não se concretizarão ao chegar ao local de destino. Outro elemento central e caracterizador do tráfico de pessoas é a exploração. Finalmente, o tráfico de migrantes é sempre transnacional, ao passo que o tráfico de pessoas pode ocorrer dentro de um mesmo território.

No caso específico dos imigrantes bolivianos existem situações nas quais as pessoas buscam alguém para facilitar sua travessia ao Brasil (tráfico de migrantes) ou são persuadidas a migrar com base em falsas propostas feitas por aliciadores (tráfico de pessoas). Abaixo segue um depoimento que ilustra o tráfico de migrantes:

Partimos de La Paz até Cochabamba e chegamos até Santa Cruz de La Sierra. Ofereceram-nos passagem para Assunção do Paraguai por USD 65,00. Chegando a Assunção nos esperava um paraguaio que nos prometeu passar a fronteira por USD 150. Ali já tinha mais gente que ofereceu levar por USD 120, optamos pelo mais barato. Chegamos a Salto del Guairá, na fronteira com Brasil, e aí ele nos prometia que ia nos fazer passar, mas não chegava o momento. Ficamos lá uma semana e o dinheiro acabava pouco a pouco. O dinheiro que tínhamos era contado para chegar ao Brasil. Cozinhamos chunio [batata desidratada], 
Paulo Illes, Gabrielle Timóteo, Elaine Pereira

lentilha e cebola e isso era o que comíamos, éramos

vários... (trabalhador imigrante, 06/09/2006).

A seguir, relato de trabalhador que ilustra a figura do tráfico de pessoas:

Meu patrão... que mora no Itaim Paulista me trouxe da Bolívia e prometeu pagar 300,00 reais por mês. Trabalhei cinco meses fechados numa casa, com cadeado, ele não me pagou nada; só um vale de 90 reais (trabalhadora imigrante, 11/09/2006).

Entretanto, o tráfico de migrantes e o tráfico de pessoas muitas vezes entrelaçam-se, pois quando os indivíduos desejam emigrar, mas não possuem dinheiro suficiente para custear toda a operação de travessia, e oferecem em garantia sua força de trabalho, fica estabelecida entre o traficante e o migrante uma relação de exploração em razão da dívida contraída. Portanto, é possivel concluir que a rede de tráfico de migrantes pode ser também um meio para a execução do tráfico de seres humanos.

\section{A mulher imigrante e suas vulnerabilidades particulares}

Estima-se que $46 \%$ dos imigrantes latino-americanos na cidade de São Paulo sejam mulheres, a maioria é jovem, dedicase ao trabalho nas oficinas de costura - em uma jornada que pode durar, em média, 14 horas por dia - e ao cuidado com os filhos. A experiência no atendimento a imigrantes no CAMI tem demonstrado que as mulheres acabam demorando mais para pedir e conseguir permanência, porque, em razão dos custos do processo de regularização, o primeiro membro da família a fazer o pedido de documentação é o homem.

A maioria dos imigrantes bolivianos, (calcula-se 90\%) trabalha em confecções (irregulares) que pertencem a coreanos, brasileiros ou mesmo bolivianos. As famílias ou 
Tráfico de Pessoas na cidade de São Paulo

vêm constituídas ou logo se formam com crianças pequenas. As mulheres são jovens (em sua maioria na faixa dos 18 aos 30 anos de idade), estão grávidas ou buscam ansiosas, meios para evitar filhos. Preferem o uso de contraceptivo injetáveis de longa duração, ao uso de preservativos como a "camisinha", devido às dificuldades de convencer e negociar com seus parceiros a realização do sexo seguro (Almeida Teles, 2008:87-88).

Além do trabalho duro - em certos casos, em condição análoga à escravidão -, as mulheres imigrantes podem estar sujeitas a diversos tipos de violências: no âmbito doméstico, nas relações em suas redes de amigos e conhecidos, no ambiente de trabalho e no acesso aos serviços públicos. Os relatos mostram suas vulnerabilidades:

...eu cuido da alimentação, da família e dos funcionários da oficina, cuido das crianças e da limpeza da casa... não tenho nenhuma atividade de lazer, meu marido joga futebol todos os domingos com os amigos... ele não me leva para passear e eu não posso reclamar... (trabalhadora imigrante, 09/04/2008).

Não pagaram meu salário durante oito meses. Quando quis cobrar, o dono da oficina me empurrou pela escada abaixo $e$ me espancou bastante. Tive hemorragia interna $e$ hematomas. Ele me chutou violentamente no estômago $e$ na vagina diretamente. Comecei a sangrar e desmaiei (trabalhadora imigrante, 23/05/2007).

Minha esposa estava a ponto de dar à luz e continuava costurando... minha filha nasceu na fila de espera, naquelas cadeiras nasceu minha filha... saindo do hospital minha esposa descansou uma semana $e$ voltou a trabalhar (trabalhador imigrante, 26/09/2006).

Muitas vezes, as mulheres são agredidas fisicamente por seus companheiros justamente por se queixarem da opressão, da falta de assistência afetiva e do alcoolismo do marido. Essa 
conduta violenta acaba contribuindo para que muitas delas silenciem diante de novos episódios.

Domingo encontrei meu marido na cama com a sobrinha do dono da oficina. Depois que vi tudo, ele me arrastou pelo cabelo e pedi socorro. Meu marido me mandou ir embora, disse que eu sou mulher e com filhos e ainda grávida ninguém vai me dar emprego (trabalhadora imigrante, 04/10/2006).

A violência sexual aparece de forma mais sutil, o que não significa que seja algo raro, pois as mulheres que sofrem esse tipo de violência são, em sua maioria, ameaçadas $e$ por isso não relatam o que lhes acontece. A própria condição de trabalhadora imigrante indocumentada faz com que ela se afaste da polícia $e$ não pratique qualquer tipo de denúncia ao poder público.

...ele era amigo de meu marido, e logo após o falecimento do meu marido me ofereceu carona e me violentou... engravidei e não tive coragem de contar a ninguém porque achei que fossem pensar que a culpa era minha... ele me ameaçou durante os nove meses de gravidez e até hoje vivo com medo... (trabalhadora imigrante, 28/05/2008).

Ademais, as trabalhadoras migrantes em situação laboral precária têm retirado o próprio direito de exercer uma maternidade responsável.

Enquanto estava costurando meus filhos ficavam trancados no quarto ou então amarrados para não colocar as mãos na máquina e não atrapalhar o rendimento do serviço. $\mathrm{O}$ patrão ficava bravo quando as crianças incomodavam. Ele também tinha filhos, eles beliscavam os meus e ninguém dizia nada (trabalhadora imigrante, 09/04/2006).

Não podemos deixar de mencionar a violência institucional muito freqüente quando tratamos do assunto imigração. Há 
Tráfico de Pessoas na cidade de São Paulo

inúmeros relatos de pessoas que passam por situações constrangedoras e humilhantes, pois não há uma política pública voltada à questão do atendimento ao imigrante. Dessa forma, muitas vezes, eles não são atendidos em hospitais $e$ unidades básicas de saúde por não conseguirem explicar o que necessitam e por não existirem pessoas habilitadas e preparadas para essa demanda, ou ainda, a assistência é negada com base em seu status migratório.

Quando fui ao posto de saúde para iniciar o tratamento pré-natal da moça que trabalha em minha casa, por ela não ter nenhum documento, foi negado o atendimento (08/07/2008).

$\mathrm{Na}$ área da educação - quando não há recusa infundada de realizar matrícula ${ }^{15}-$, muitas crianças sofrem discriminação $e$ problemas de adaptação na escola, resultando em um afastamento de serviços básicos que independem do status migratório. Esse afastamento contribui para um isolamento social $^{16}$, fazendo com que esses imigrantes permaneçam despercebidos aos olhos da sociedade.

\section{Conclusão}

A repressão à exploração de imigrantes em situação irregular em São Paulo tem resultado, muitas vezes, na deportação das vítimas. As diligências do Ministério Público e da Polícia Federal geram a proliferação das oficinas de costura irregulares para outras regiões da cidade - Santo Amaro, Campo

\footnotetext{
${ }^{15}$ Ver nota 11.

${ }^{16}$ Entende-se por isolamento social a ausência de contato entre pessoas - seja ele direto ou indireto. Pode ser causado por processos sociais ou individuais que ocorreram na infância ou durante a fase de isolamento. As atitudes de ordem social remetem ao preconceito e as de ordem individual são aquelas particulares, como a timidez.
} 
Limpo, Casa Verde, Grande São Paulo (Guarulhos, Cotia, Jandira e outras) - e para cidades do interior de São Paulo (Americana, Piracicaba, Bragança e outras). Assim, a cadeia de exploração vem achando formas de se reinventar.

Entendemos que o problema da imigração irregular deve ser trabalhado em duas frentes: no país de origem e no país de destino. Em ambos os lugares, tanto as mulheres como os homens devem ter as mesmas oportunidades de trabalho com eqüidade salarial, acesso à educação, e políticas públicas que possibilitem a igualdade de gênero. Entretanto, como destaca Lisboa (2007: 820),

as políticas sociais, na sua grande maioria, têm sido elaboradas por homens, que não levam em consideração as reais demandas das mulheres, contribuindo em alguns contextos para a reprodução da sua subalternidade.

Nesse sentido, acreditamos que é necessário lutar para a construção $e$ implementação de políticas públicas para os imigrantes, independente de seu status migratório, sem perder de vista que essas políticas devem estar atentas às demandas particulares das mulheres imigrantes - como as destacadas neste artigo.

Uma política pública que atente para o fenômeno migratório deve ter como base a proteção dos direitos humanos dos imigrantes. Norteando-se por este indicativo principiológico, é necessário formular e implementar políticas públicas que considerem aspectos específicos vinculados à imigração. É preciso que o poder público atue no sentido de propor soluções às principais necessidades dos imigrantes, objetivando, assim, um tratamento adequado a esse seguimento da população presente em nosso país. Tal intento é, de fato, um desafio trazido pela imigração, porém, é necessário que as políticas públicas se adaptem a essa nova realidade. 
Tráfico de Pessoas na cidade de São Paulo

\section{Referências bibliográficas}

Almeida Teles, Maria Amélia de. Imigrantes bolivianas em São Paulo: a dupla invisibilidade. In: SPM-IRLS. No Somos Estranjeros... São Paulo, Expressão Popular, 2008.

AzEVEDo, Flávio Antônio Gomes de. A presença de trabalho forçado urbano na cidade de São Paulo: Brasil/Bolívia. Dissertação de Mestrado, PROLAM/USP, 2005.

ENTZINGER, Han. Novas Tendências Migratórias à Escala Mundial. http://www.casadobrasil.info/UserFiles/File/pdfs/novas-tendenciasmundial.pdf.

LisBOA, Teresa Kleba. Fluxos migratórios de mulheres para o trabalho reprodutivo: a globalização da assistência. Revista Estudos Feministas (15), Florianópolis-SC, Setembro/Dezembro de 2007.

PatUSSI, Roque. Bolivianos em São Paulo: Travessia na De\$ordem Global: Fórum Social das Migrações. São Paulo, Paulinas 2005.

SEZYSHTA, Arivaldo José. Migração Nordestina: A contínua saga de um povo. Cadernos do Ceas (214), Salvador, Centro de Estudos e Ação Social, Novembro/Dezembro, 2004.

SEYFERTH, Geralda. Imigração no Brasil: os preceitos de exclusão. http://www.comciencia.br/reportagens/migracoes/migr03.htm.

SILVA, Sidney Antonio da. Bolivianos em São Paulo: entre o sonho e a realidade. Estudos Avançados (20), São Paulo, Maio/Agosto de 2006.

\section{Outras fontes}

Acordos multilaterais devem ajudar migrantes. http://www.onu-brasil.org.br/view_news.php?id=3879

BRASIL. Decreto n ${ }^{\circ}$ 5016/04. http://www.planalto.gov.br/ccivil_03/_Ato20042006/2004/Decreto/D5016.htm

BRASIL. Decreto n ${ }^{\circ}$ 5017/04. http://www.planalto.gov.br/ccivil_03/_Ato20042006/2004/Decreto/D5 017.htm

BRASIL. Deliberação CEE no 16/97 - São Paulo. http://www.crmariocovas.sp.gov.br/pdf/diretrizes_p0860-0865_c.pdf 
Paulo Illes, Gabrielle Timóteo, Elaine Pereira

BRASIL. Resolução SE n 10 de 2 de fevereiro de 1995 - São Paulo. http://siau.edunet.sp.gov.br/ItemLise/arquivos/10_1995.htm

Cresce número de imigrantes em busca do sonho brasileiro. http://www.bbc.co.uk/portuguese/reporterbbc/story/2008/03/080320_i migracaoeldoradobrasil.shtml

Isolamento social. http://mundoeducacao.uol.com.br/sociologia/isolamento-social.htm http://www.brasilescola.com/filosofia/ isolamento-social.htm

Migrações Sul-Sul já são metade do total. http://historiafunbbe.blogspot.com/2008/06/migraes-sul-sul-j-sometade-do-total.html

Renda de migrantes tira 2,5 mi da miséria na $A L$. http://www.onu-brasil.org.br/view_news.php?id $=4616$

Tráfico de Pessoas ou Contrabando de Estrangeiros? http://usinfo.state.gov/journals/itgic/0603/ijgp/gj09.htm 